\title{
A Quantitative Study of Maltese Primary School Teachers and Their Perceptions Towards Education for Sustainable Development
}

\author{
Marilyn Cordina, Mark C. Mifsud \\ University of Malta, Msida, Malta
}

\begin{abstract}
The study aims to explore Maltese primary school teachers' perceptions towards Education for Sustainable Development (ESD). The research focused on 3-6 years old Maltese educators' level of ESD awareness and knowledge, their attitudes towards ESD, and their willingness to adopt ESD within the classroom setting. Primary teachers' ESD methodological skills were investigated as were issues that hinder ESD adoption as a regular teaching tool. The quantitative research involved the collection and analysis of 271 questionnaires. This data was plotted on graphs and analysed through Statistic Package for Social Science (SPSS) statistical tests. The findings show that in general, junior years' primary school teachers show interest in implementing ESD and exhibit a positive attitude towards the area. However, it was noted that the participants' level of awareness and knowledge of the various ESD concepts are rather low or unclear. Notwithstanding, many educators integrate ESD values and skills in their teaching methodology unconsciously. Several obstacles are shown to impede educators in their attempt to integrate ESD to its full potential. The main findings from the research were used to construct a model that visually illustrates the relationships between the variables and drafts a list of recommendations.
\end{abstract}

Keywords: Education for Sustainable Development (ESD), knowledge, attitudes, behaviour, primary educators

\section{Introduction}

In 2012, the Maltese National Curriculum Framework (NCF) marked the significance of Education for Sustainable Development (ESD) in the Maltese educational system by listing it as one of its goals. The NCF considers ESD to be one of the five cross-curricular themes throughout education giving special attention to the junior and secondary school cycles. It asks for the re-orienting of our educational system into one which addresses sustainable development values and practices, and

respects, values, and preserves past achievements; values the Earth's resources and its peoples; strives towards a world in which all humans have access to sufficient food and water, a healthy and productive life, basic education, and a safer and just environment; [and] assesses, cares for and restores the state of our planet; develops citizens who exercise their rights and responsibilities locally, nationally and globally. (United Nations Educational, Scientific, and Cultural Organization [UNESCO], 2006, as cited in Ministry of Education and Employment, 2012)

From then onwards, the implementation of ESD ceased to be an option based upon personal interest for

Marilyn Cordina, M.A., Centre for Environmental Education Research (CEER), University of Malta.

Mark C. Mifsud, Ph.D., Centre for Environmental Education Research (CEER), University of Malta. 
Maltese educators and became an obligation. Thus, this research probes into primary school educators' attitudes, knowledge, and behaviour towards incorporating environmental education (EE)/ESD knowledge and methodological techniques into their teaching. As Wals and Kieft (2010) affirmed, when studying EE and ESD implementation in Western and Non-Western contexts,

despite the undeniable progress that has been made around the world [as regards the area], there still exists a number of common ESD implementation challenges including lack of financial and governmental support and coordination the lack of common understanding and awareness of ESD and the lack of ESD capacity building. (p. 8)

Furthermore, as Mifsud (2012) argued that effective EE in formal schooling in Malta is hindered by "the dominant educational ideology that suppresses creativity and rewards rehearsed words in examinations, ... [by] little timetable time and [by] lack of locally produced resources" (p. 61).

Thus, some Maltese educators might find even more challenging the introduction of obligatory ESD's "transformative [process of] ... managing change such that people are provided with not only knowledge and understanding, but also skills and capacity to administer change while recognising the relationships between environmental protection, economic prosperity, and social cohesion" (Stevenson et al., 2013, p. 157). Moreover, as stated by McKeown (2002), "Because sustainable development is hard to define and implement, it is also difficult to teach. Even more challenging is the task of totally reorienting an entire education system to achieve sustainability" (p. 30).

Various international researchers investigated how educators or pre-service teachers perceive ESD. As Buchanan (2012) pointed out that, "Sustainability education did not enjoy a common understanding among participants [of a primary education programme $\ldots$ and that] a range of sustainability education engagement in various subjects [was observed, in particular] in Social Sciences and Science.” The inclusion of ESD was, however, confined to a cross-curricular subject called Society, Science, Technology, and the Environment. This consists of the study of three sites and connected environmentally issues. These findings demonstrate that beyond the activities included in the last-mentioned subject "evidence of inclusion of sustainability [as a cross-curricular theme within the participant's university], proved to be incidental in nature" (Buchanan, 2012, p. 114).

Ryan (2004) explored that the final year teacher education students' knowledge and attitudes of sustainable development towards ESD and how these interrelated with their perception of the primary teacher's work (p. 225). This researcher established that,

The students' responses indicated that they would be predisposed towards a committed form of [ESD], at least in terms of process. However, they demonstrated little of the requisite knowledge, understanding, and attitudes [and] little concern or awareness of the need for sustainable development... [Furthermore], although they might have been happy for their pupils to take a socially critical approach, the students did not appear to see the need to engage in the process of change themselves. (Ryan, 2004, p. 234)

Saka and Sahintürk (2013) discovered that a lack of cross-curricular practice in implementing ESD and concluded "that, in order to make individuals adopt sustainability as a life philosophy, interdisciplinary cooperation is needed [and that] this cooperation should be included in the curriculum of different fields of study" (pp. 1556-1557). Furthermore, Saka and Sahintürk (2013) established that "the participants view sustainable development from an environmental perspective only" (p. 1557).

Bursjöö's (2011) findings indicate that participants' "motivation to educate for sustainable development is strongly expressed... but they experience many barriers for the implementation of ESD, external as well as 
internal' (p. 73). Additionally, according to Bursjöö (2011), educators feel overwhelmed by tensions between their expected professional responsibilities in teaching ESD when set against personal limitations, as well as conflicts with other educators, principals, and the public (p. 59).

Furthermore, Adawiah and Norizan (2012) noted that 'in-service teachers' overall knowledge about the concept of ESD is good. However, ... some teachers hold misconceptions [on the topic].... They understand the three components [of the pillars of] ESD, but the understanding about the interrelationships between them is still minimal" (p. 836).

Michail, Stamou, and Stamou's (2006) study showed that "teachers held several environmental knowledge gaps and misconceptions" and that they were "using the media as a major environmental information source, in which environmental issues are constructed as environmental risks, [resulting in] teachers... being environmentally educated in lay and not in scientific terms" (p. 257).

A positive attitude towards ESD principles was also discovered by Chunteng when surveying primary and secondary school teachers' teaching competences for EE. Despite this, Chunteng (2004) argued that these attitudes were found to be affected negatively by the participants' lack of knowledge and awareness. As this researcher affirms, since "teachers lack an overall understanding of the connotation of environmental education, ... [they] are not sensitive to the contents related to environmental education in the teaching of their own subjects, ... [whilst they also] overlook the personal experience and practices of the students" in this area. Furthermore, Chunteng's results showed a "lack [of teacher] cooperation and communication among different subjects" (p. 42).

Robertson and Krugly-Smolska's (1997) study revealed that teachers "find that EE is a difficult task within the realm of schools... onapractical, ... conceptual, ... [and] responsibility levels.” These researchers established that "many teachers continue to believe that [EE] belongs within the domain of science... [and that they have the] assumption that exposure of students to certain activities or experiences is sufficient to bring about change in attitudes and behaviours' (Robertson \& Krugly-Smolska, 1997, p. 318). They also emphasise the fact that,

It appears that there are societal influences that keep teachers from treading on delicate ground in the spirit of EE ... [and that] teachers feel constrained by the apparent number and complexity of tasks to be done and by other competing demands within their profession. (p. 322)

Athanasios, Polyxeni, and Anastasios (2006) also discovered that a large number of teachers request training in order to feel confident in delivering ESD. Results showed that,

Environmental educators are informed about the concept of sustainable development, its characteristics, the stakeholders who are responsible for planning and materialising its goals and tools for its implementation, [but] they have not reached the full understanding of the conceptual context of [ESD]. (p. 186)

\section{Background to This Study}

In Malta, the tradition of environmental topics in schools "can be traced back to the earliest school circulars issued between 1853 and 1858" (Ventura, 1994, p. 18). However, official EE was initiated in the 1960 's by a number of "interested individuals [who] came together and set up the first local environmental Non-Governmental Organization (NGO) with the main aim of increasing public awareness about particular species which have been persecuted locally" (Mifsud, 2012, p. 53). 
By 1969, the importance of EE grew with the suggestion of integrating environmental issues and other subjects using a child centred methodology. In 1982, social studies, including environmental aspects were introduced in the junior years of primary schooling whilst a science curriculum was devised in 1989 (Ventura, 1994, p. 18). In 1992, the introduction of local Matriculation and Secondary Education Certificate Examinations Board launched new syllabi more attuned to the local context. Thereafter environmental issues were tackled through Social Studies, Science, Environmental Studies, and Environmental Science (Pace \& Brigulio, 2004, p. 2).

A National Environmental Education Strategy developed in 1995, attempted to follow the Agenda 21 guidelines on "directing educational processes towards the development of a new environmental ethic-education for sustainability" (Brigulio \& Pace, 2004, p. 4, as cited in University of Malta, 1995). However, "limited resources" and lack of interest from the target groups regarding EE as "a priority" rendered "their participation in the consultation process... inadequate" (Pace \& Brigulio, 2004, p. 4).

Without any direct mention of EE or ESD, the National Minimum Curriculum published in 1999, laid the first steps towards tackling EE and ESD in formal schooling. It recognised the need for "the people of Malta to be able to understand and tackle the threats posed by contemporary societies to the... environment," and "to understand the social and environmental effects of different patterns of consumption [and] appreciate the values of cooperation and solidarity" and of "safeguarding the natural environment in a sensitive manner." It highlighted the "link between science and technology" and the "great effects" that the development "of each has on the quality of life and the natural environment." It imposed the observation of

the code of ethics governing science and technology and the norms with regard to security and the safeguarding of the natural environment. [It encouraged] students'... knowledge/information [of]... their rights and responsibilities in relation to... themselves, the community, the country, the natural environment and animals, [and] "participat[ion] in environmental protection initiatives. (Ministry of Education, 1999)

The entire document emphasised the importance of developing a "democratic spirit by the school's ability to arouse curiosity and stimulate critical and creative thinking among children" (Ministry of Education, 1999, p. 15).

Despite the Education Ministry's attempt to enhance EE in schools by distributing a handbook on how to integrate it across the curriculum, environmental issues continued to be almost entirely tackled by the four above-mentioned subjects by EkoSkola and by DinjaWahda school programmes run by NGOs.

The latest official attempt for enhancing ESD practice were the goals and objectives set in the National Curriculum Framework published in 2012 (Ministry of Education and Employment, 2012, p. 37). Since its publication, very little research has been carried out locally to study ESD's effective implementation as a cross curricular teaching tool through understanding educators' knowledge, attitudes, and behaviour towards ESD.

Local researchers, such as Mifsud (2011), Baldacchino (2011), and Portelli (2011), focused on students' and youth's, rather than teachers' attitudes towards sustainability. Others, such as Aguis, Chetcuti, and Galea (1996) and Buhagiar and Gatt (2006), investigated EE and ESD at a curriculum level while other local studies have investigated University of Malta students' perceptions on EE. Various researchers also examined the implementation and evaluation of curriculum packs in line with the EkoSkola programme principles.

After a review of the available national and international literature pertaining to the subject a set of research questions were devised. The main research question for this study was: 
What are Maltese primary teachers' perceptions of ESD?

The secondary questions that emerged from the above inquiry are:

1. What are teachers' present levels of awareness/knowledge of the various concepts when related to ESD concepts?

2. What are teachers' attitudes towards ESD and what is their willingness to adopt ESD within their classroom setting?

3. What skills and styles do teachers use to promote ESD in their day-to-day teaching, if any?

4. What are the issues that hinder the adoption of ESD as a regular teaching tool?

\section{Method}

This study mainly opts for quantitative data collection and analysis procedures. A questionnaire was developed and distributed to collect the quantitative data. Nonetheless, the questionnaire included a number of areas in which open-ended questions were provided to collect qualitative data to give deeper meaning to the numbers. The stakeholders for the study consisted of educators teaching junior primary school classes. Their age, gender, years of teaching experience, level of education, and school sector in the primary educational system varied.

The sample size for the quantitative study was calculated upon a population of 1,419 primary educators guaranteeing a $95 \%$ confidence level and a $4.5 \%$ confidence interval from a list of 62 state schools, 28 Church schools, and nine independent schools. The initial intention was to sample the total population of all the schools in Malta and Gozo. However, this turned out to be impossible, because certain schools refused permission to the author to distribute the questionnaire. Thus, 750 questionnaires were distributed amongst the available population of 64 schools in all through hard copy and online forms. The response rate was of $40 \%$ resulting in the collection 271 valid questionnaires.

The quantitative data was analysed around the identified key themes that emerged from the literature review and consequently shaped the research questions. These were: teachers' ESD perceptions; knowledge; attitude; behaviour; and issues that hinder ESD.

The sections in the questionnaire checked for the following:

1. Section A: Demographic data;

2. Section B: Overall perceptions of ESD;

3. Section C: Educators' perceptions and specific knowledge and awareness of ESD;

4. Section D: Attitudes towards ESD;

5. Section E: ESD behaviour within the classroom setting;

6. Section F: Issues that enhance or hinder ESD implementation.

The question responses were plotted on graphs and tested for variable differences through Statistic Package for Social Science (SPSS) Kruskal Wallis, Mann Whitney $U$ and Pearson Chi-Squared tests. SPSS Spearman correlations were also carried out to check variances between attitudes and behaviour, knowledge and behaviour, knowledge and attitudes, and certain attitudes with others.

After the completion of the quantitative data analysis, any information gaps and areas which still needed to be clarified were identified. The open-ended question in Section F provided valid data in this regard. Consequently, a semi-structured interview tool for the qualitative part of the study, which will not be discussed here, was devised. 
This study was limited by a number of factors. The low acceptance rate at distribution level made the initial part of the research more time consuming and very difficult to be carried out. Educators' lack of trust in the confidentiality level of the research and their reluctance in completing the questionnaire due to the high demand of questionnaires that are currently being given to them, added on to the difficulty in collecting the quantitative data. Thus, despite the extensive effort made, the authors were not successful in reaching the set quota. The authors closed the distribution phase at the collection of 271 questionnaires since the sources were exhausted. The fact that the adequate sample size was not reached meant that the results for this study can only be representative of the number of participants studied (see Figure 1).

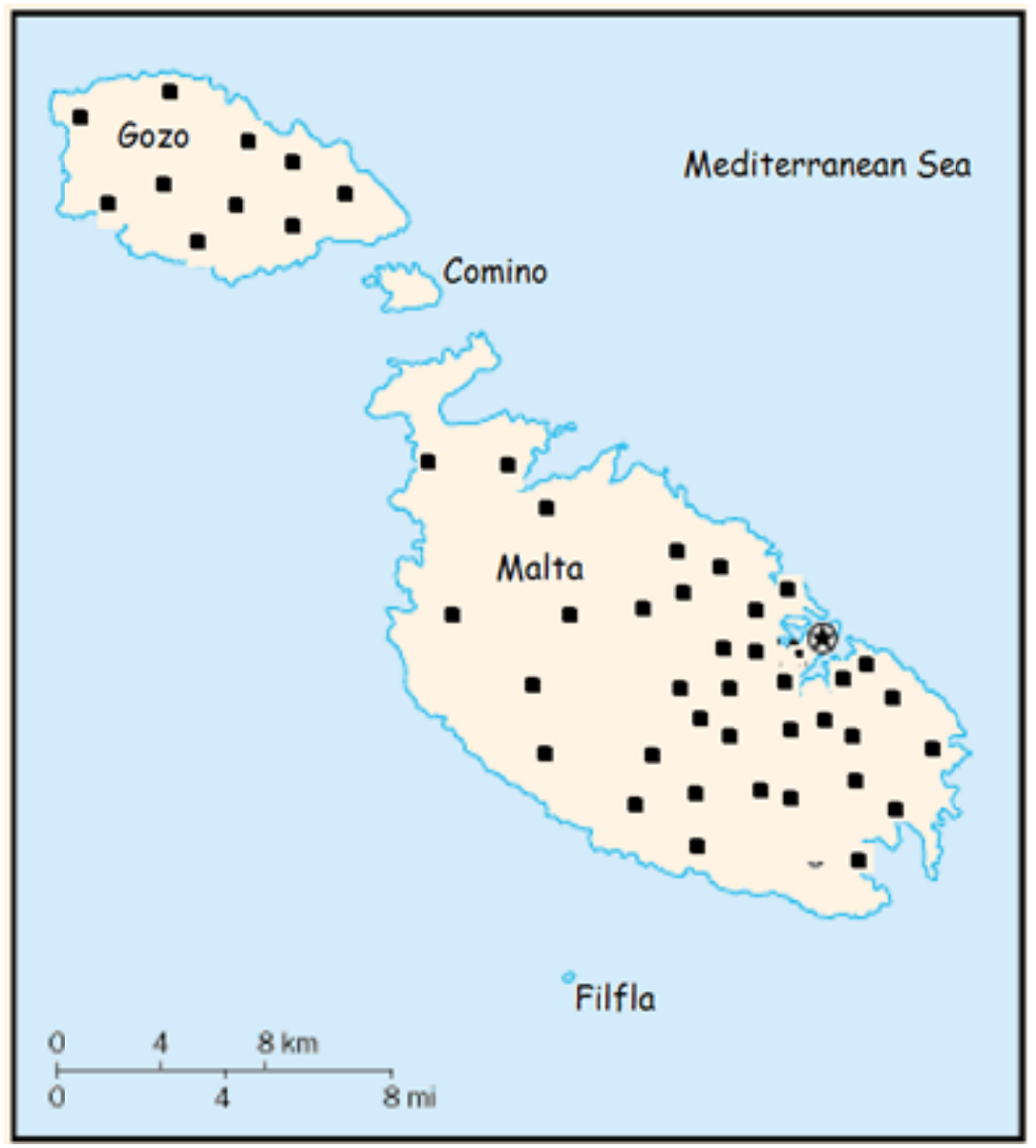

Figure 1. Areas from which data was collected. Some dots refer to more than one participating schools due to their physical closeness.

\section{The Findings}

This study investigated some of the Maltese primary teachers' ESD perceptions. It sought to find teachers': ESD level of awareness and knowledge; attitudes towards implementing ESD; ESD methodological skills; and difficulties in adopting such strategies.

\section{Educators’ Knowledge and Awareness of ESD}

The findings to this study show that educators' overall perceptions on ESD are restricted or imprecise. Only one quarter of the respondents could give a clear definition of the term ESD (see Figure 2). These 
definitions were mostly related to the Brundtland term or linked to EE. The other participants had a partial understanding, or no understanding at all of what ESD entails.

\section{In your opinion what is education for sustainable development}

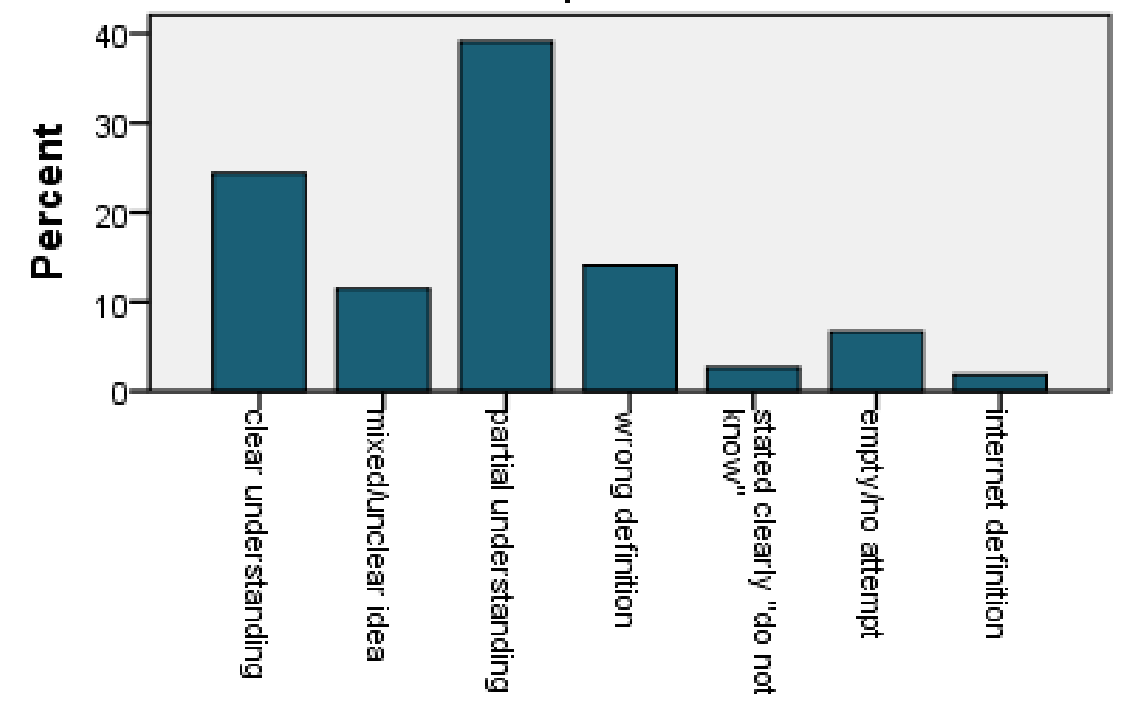

Figure 2. Definitions of ESD.

Some interesting replies in the open-ended questions to the above were:

I do not know... maybe it is about the environment and animals around us (36-48 years, female, church school, and 15 years of teaching experience).

Sustainable development is a development that meets the needs of the present without compromising the ability of future generations to meet their own needs (36-48 years, female, state school, and seven years of teaching experience).

ESD is a means by which we take care of the world around us (22-35 years, female, independent school, and six years of teaching experience).

It is a way in which we help learners develop in conscious and critical thinkers, so that they can be able to make intelligent decisions (22-35 years, male, state school, and one year of teaching experience).

A close analysis of how educators ranked different terms that describe ESD shows that the highest-ranking terms were related to descriptions portraying ESD as a knowledge oriented subject addressing individuals attending formal schooling only. On the other hand, the lowest ranking terms were associated to ESD as skills and values oriented within the formal, non-formal and informal educational system. In addition, more than half of the respondents to the study associate ESD exclusively to the environmental sector, ignoring the other important facets of ESD.

This study also shows that teachers possess knowledge on some important aspects concerning ESD but are misinformed on many others. Educators' disjointed knowledge of ESD is shown in the contrasting responses to connecting questions (see Table 1). Approximately, the same amount of participants simultaneously agreed (33.6\%) and disagreed (35.4\%) that ESD is mainly about teaching information about sustainable development. On the other hand, the vast majority of the participants agreed to some extent or other $(88.3 \%)$ that ESD develops problem-solving, decision-making, and critical-thinking skills in the survey. These contrasting results clearly show that educators demonstrate important inconsistencies and misunderstandings regards ESD. 
Table 1

Teacher's Knowledge of ESD

\begin{tabular}{lll}
\hline Teacher's knowledge of ESD & $N$ & Mean \\
\hline ESD is a tool to achieve a more sustainable future. & 265 & 1.5057 \\
ESD develops problem-solving, decision-making, and critical-thinking skills. & 263 & 1.6350 \\
ESD prompts individuals to become actively involved citizens. & 260 & 1.6500 \\
ESD engages formal, non-formal, and informal education. & 262 & 1.6832 \\
ESD promotes values like solidarity, equality, democracy, respect, tolerance, and social justice. & 261 & 1.7050 \\
ESD encourages learners to look at the roots of an issue before taking action. & 251 & 1.7052 \\
ESD associates the ecological, social, cultural, and economic dimensions. & 250 & 1.7160 \\
ESD prompts the individual in active involvement in the local community. & 260 & 1.8423 \\
ESD entails learners to forecast possible futures based on different scenarios. & 253 & 1.8498 \\
ESD incorporates local, national, and global dimension in the study of an issue. & 250 & 1.8720 \\
ESD calls for reorienting existing education to one which includes knowledge, skills, issues, & 241 & 1.9087 \\
perspectives, and values. & 221 & 2.1629 \\
ESD encourages individuals to consider ancestral sustainable practices as examples to follow. & 259 & 2.5290 \\
ESD is mostly teaching about the natural surroundings. & 244 \\
ESD fosters environmentally responsible attitudes and behaviours. & 217 \\
ESD leads to intra-national and international agreement. & 256 & 2.5697 \\
ESD promotes relations and interdependencies. & 232 & 2.6544 \\
ESD can be easily imported from another cultural, economic or geographical region. & 251 & 2.6680 \\
ESD is mainly about teaching information about sustainable development. & 258 \\
ESD is primarily addressed to young people and school students. & 252 \\
ESD considers environmental damage to be reversible. & 136 & 3.9840 \\
Valid $N$ (list wise) & 3.2024
\end{tabular}

\section{Educators’ Attitudes Towards ESD}

In contrast with the above stated results, a positive attitude towards ESD implementation is manifested by the participants. The majority of participants express willingness to adopt ESD within their teaching (see Figure 3).

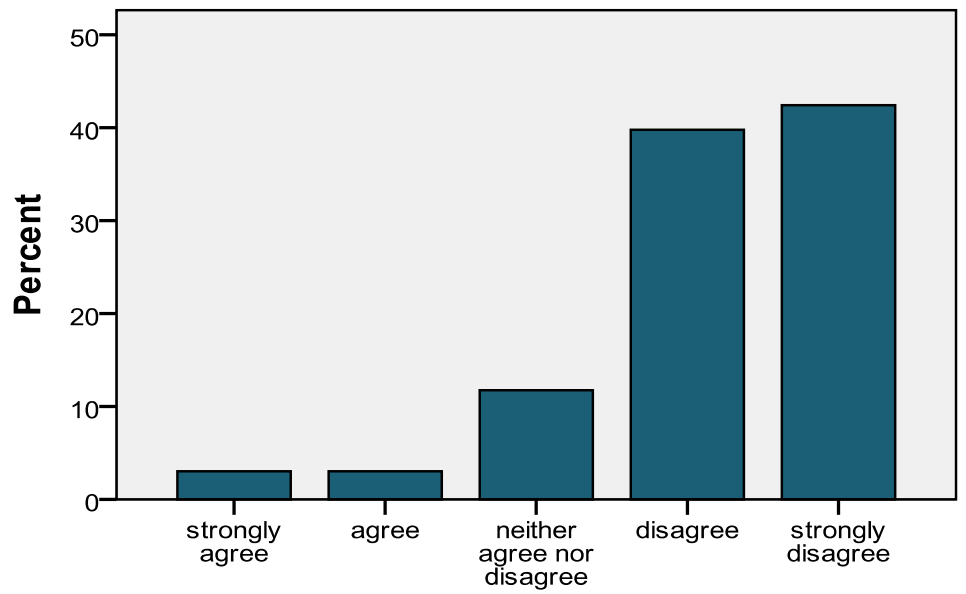

Figure 3. The authors feel unwilling to deliver ESD as they do not share the same values and perspectives.

In addition, more than half of the respondents $(69.3 \%)$ believed that ESD integrated into the primary school curriculum is vital for achieving sustainability. 
Furthermore, this study portrays many respondents' positive outlook to sustainability who are affected positively by their personal values to implement ESD. A positive outlook towards the integration of ESD can also be noted in the educators' predisposition for training. In fact, an over-all need for ESD training and guidelines prevailed amongst respondents of this study. A vast majority of the respondents (66\%) indicated that they would feel more confident in implementing ESD after attending compulsory training. A slightly lower but not significant variance (59\%) is noted in educator's inclination to attend ESD on-going voluntary training (see Figure 4).

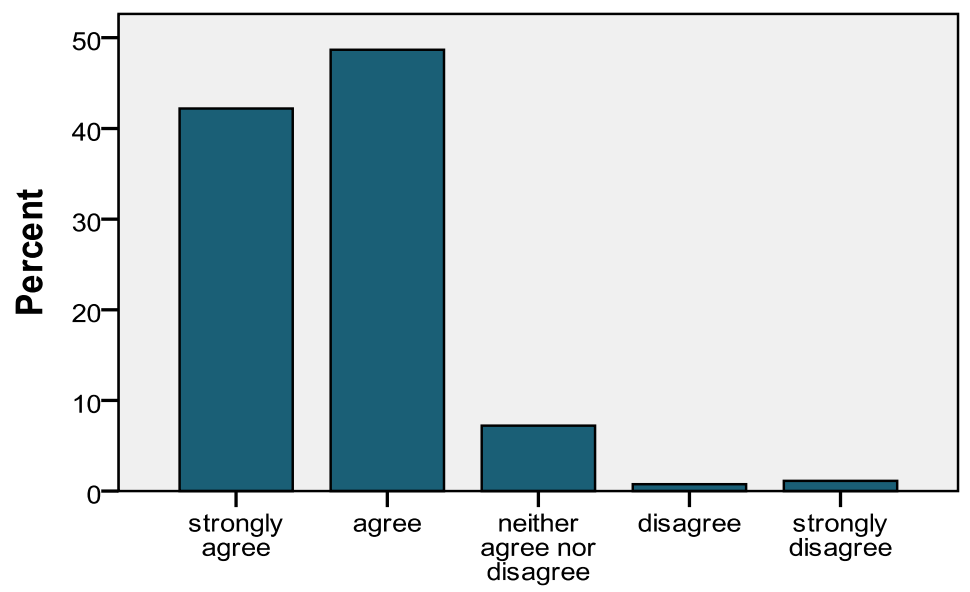

Figure 4. The authors would feel more confident in implementing ESD if a locally valid Toolkit with sample lesson plans and worksheets is available.

Almost all participants feel the need of a locally valid toolkit with sample lessons plans and worksheets.

This study also portrays educators' widespread willingness to actively participate in the shaping of ESD resources themselves and a general predisposition amongst teachers to collaborate with colleagues to shape a culturally and socially valid ESD program for their class (70.9\%). Furthermore, in line with the National Curriculum Framework proposals, the majority of the respondents $(72.3 \%)$ agreed that ESD should be tackled in a cross-curricular manner across all subjects (see Figure 5).

Contrasting the above results, however, is the fact that only just over half of the respondents feel fully responsible for the sustainable development values and practices that their learners develop.

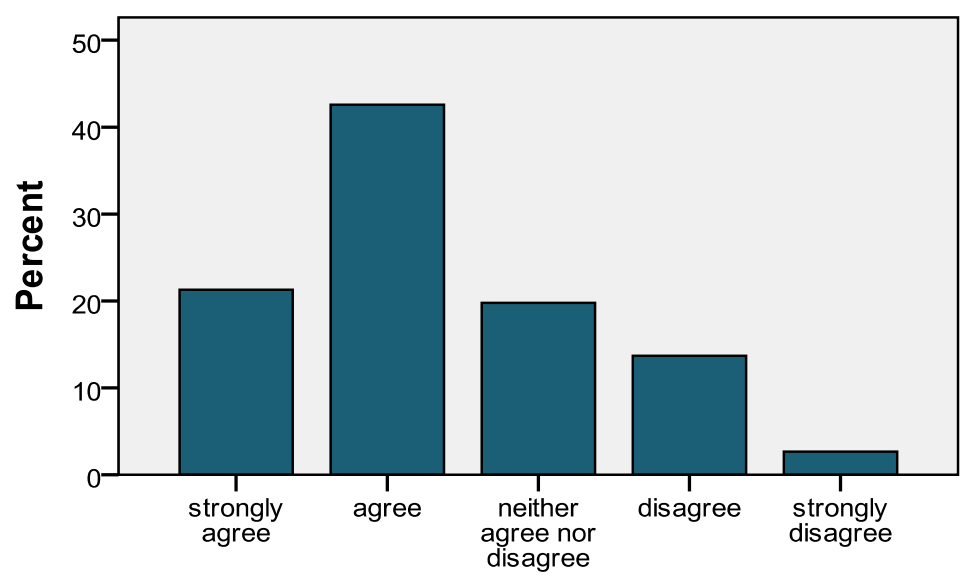

Figure 5. The authors feel fully responsible for the sustainable development values and practices that their learners develop throughout the scholastic year under my supervision. 


\section{Implementation of ESD}

A significant finding of this study is that despite the low level of knowledge exhibited by many participants, they still scored fairly well in some aspects when asked about ESD behaviour within their classroom setting. This study shows that many educators amalgamate ESD methodological skills and values into their daily teaching strategies. Moreover, the vast majority of the participants (75.4\%) feel that they are pro-environmental role models in their behaviour and upholding of sustainable practices.

These findings show that educators rank ESD behaviour that has to do with respect towards others, towards themselves and towards all living creatures quite highly (see Table 2). The most valued ESD skill by the vast majority of educators was promoting a sense of community within their classroom. Furthermore, the participants regard highly the instilling of respect towards all living creatures, together with values of peace, solidarity, and mutual respect between individuals. Promoting healthy lifestyles, good listening, expression skills, and discussing cultural, religious, and ethnic diversity are also regarded as key factors by educators.

Table 2

ESD Behaviour Within Classroom Settings

\begin{tabular}{lll}
\hline ESD behaviour & $N$ & Mean \\
\hline Bringing community resource people into the classroom as content experts. & 2.1513 \\
Using data relating to aspects of sustainability during data handling and analysis. & 271 & 2.4982 \\
Promoting competition between class members. & 271 & 2.6900 \\
Taking students for educational fieldtrips with an ESD issue in mind. & 271 & 2.7343 \\
Use role-play to encourage understanding of different points of view. & 271 & 3.1624 \\
Evaluate and try to minimize the environmental impact of an activity or an outing. & 271 & 3.4428 \\
Guiding discovery-based learning through investigation. & 271 & 3.4465 \\
Hold debate and discussion sessions. & 271 & 3.5904 \\
Using group work as a teaching and learning strategy. & 271 & 3.9074 \\
Discussing cultural, religious, and ethnic diversity. & 270 & 3.9373 \\
Making pupils probe an idea before accepting or discarding it. & 271 & 4.3210 \\
Role modelling of pro environmental behaviour and sustainable practices. & 271 & 4.4170 \\
Giving pupils the possibility to evaluate and solve any dispute risen while at school. & 271 \\
Encouraging students to take their own decisions. & 271 & 4.4428 \\
Prompting creativity in fulfilling a task and accepting various possible conclusions. & 271 & 4.5277 \\
Promoting values of peace, solidarity, and mutual respect. & 271 & 4.5609 \\
Promoting good listening and expression skills. & 271 & 4.9114 \\
Promoting healthy lifestyles. & 271 & 4.9373 \\
Promoting respect towards all living creatures. & 271 & 5.2030 \\
Promoting a sense of community within your classroom. & 271 & 5.3210 \\
Valid $N$ (list wise) & 271 & 5.3985
\end{tabular}

In contrast, the abilities shown by teachers in using collaborative teaching strategies with pupils scored rather low. Only little more than half of the participants use group work as a teaching and learning approach on a regular basis (see Figure 6).

A small percentage of the participants (33.6\%) use role-play habitually to encourage understanding of different viewpoints. Slightly more than half of the respondents $(55 \%)$ use competition between their class members to different degrees, mostly occasionally. 


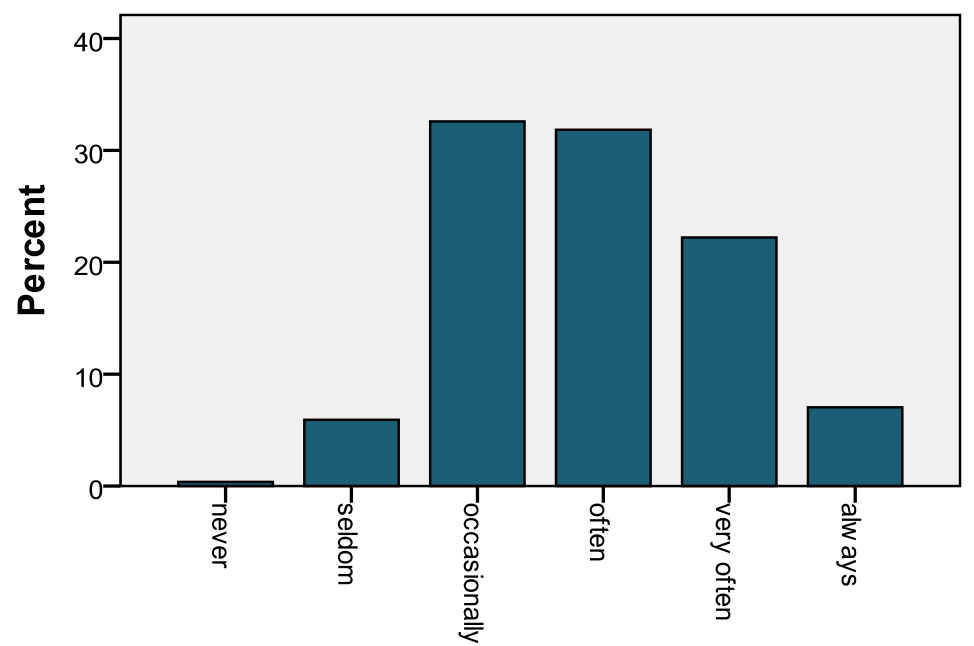

Figure 6. Using group work as a teaching and learning strategy.

A lack of collaboration also featured in educators' teaching methodologies since only a minimum of the participants take advantage of the effective learning outcomes of bringing community resource people into the class (see Figure 7).

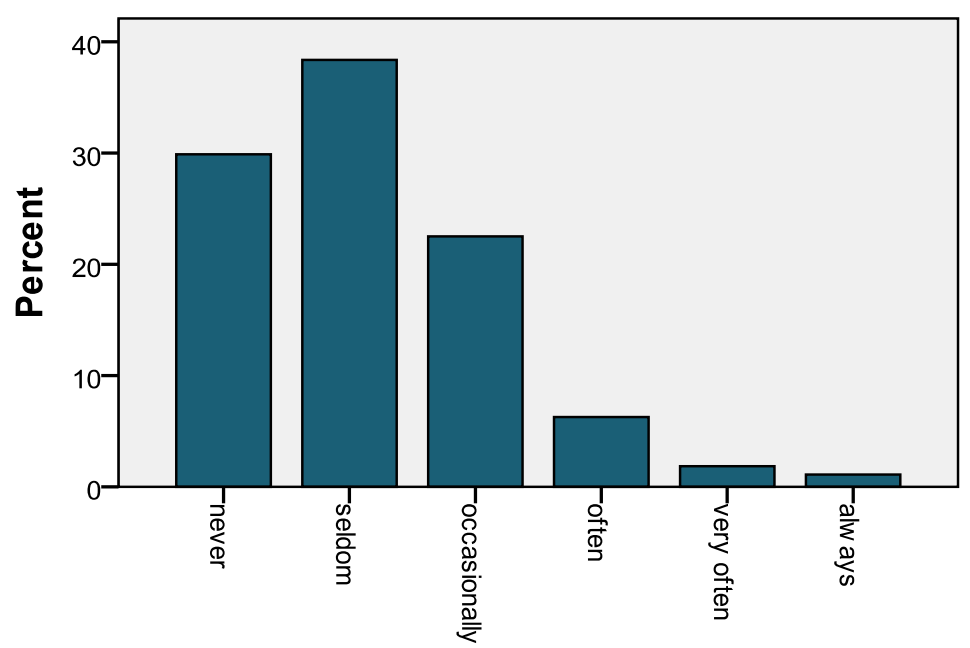

Figure 7. Bringing community resource people into the classroom as content experts.

Despite the favourable results which show that the majority of the respondents agree that ESD should be tackled in a cross-curricular manner across all subjects (72.3\%), the existence of a low cross-curricular mentality on the part of educators emerged. Less than half of the participants (46.5\%) to the quantitative part of the study use the cross-curricular aspect between maths and ESD, most of which do it occasionally.

Educators make use of critical and creative thinking skills through experiential methodologies on different levels. The majority of teachers regard highly the importance of promoting creativity in fulfilling a task, and of promoting decision-making and evaluation processes amongst their pupils (see Figure 8).

In contrast, slightly less than half of the participants (49.1\%) hold debate sessions with their class on a frequent basis. Furthermore, only about one quarter of the participants (21.4\%) regularly proposed outings with an ESD issue in mind, whilst less than half of them (46.5\%) gave their pupils the possibility to evaluate the environmental impact of a planned outing and to assess how they could minimise it customarily. 


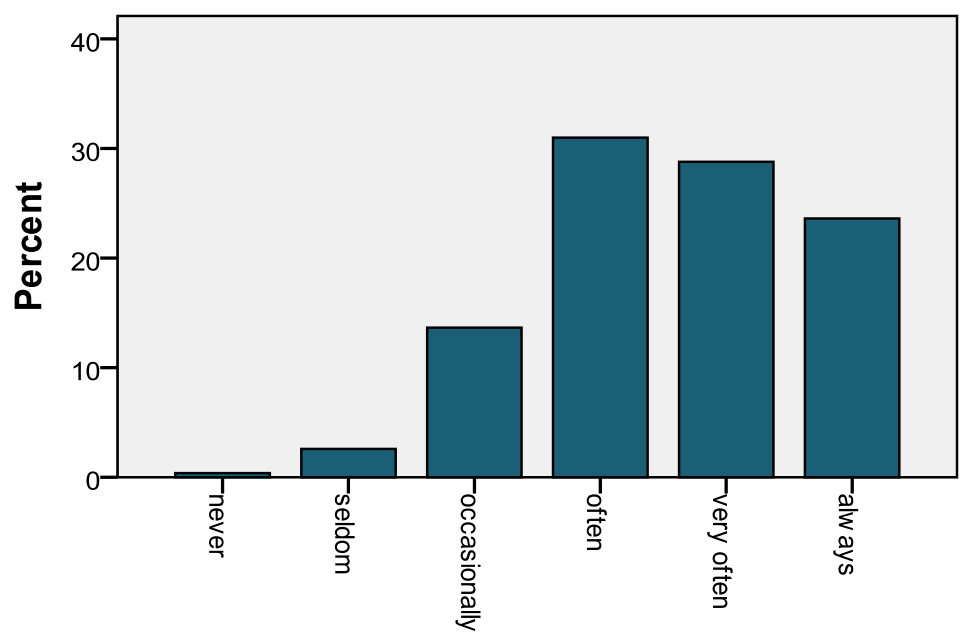

Figure 8. Prompting creativity in fulfilling a task and accepting various possible conclusions.

\section{Issues That Enhance or Hinder ESD Implementation}

Despite educators' positive attitudes and ESD instilled behavioural traits that emerged from this study, many obstacles hinder holistic ESD implementation. It is noted that only half of the participants feel sufficiently knowledgeable about ESD issues and methodology (see Figure 9).

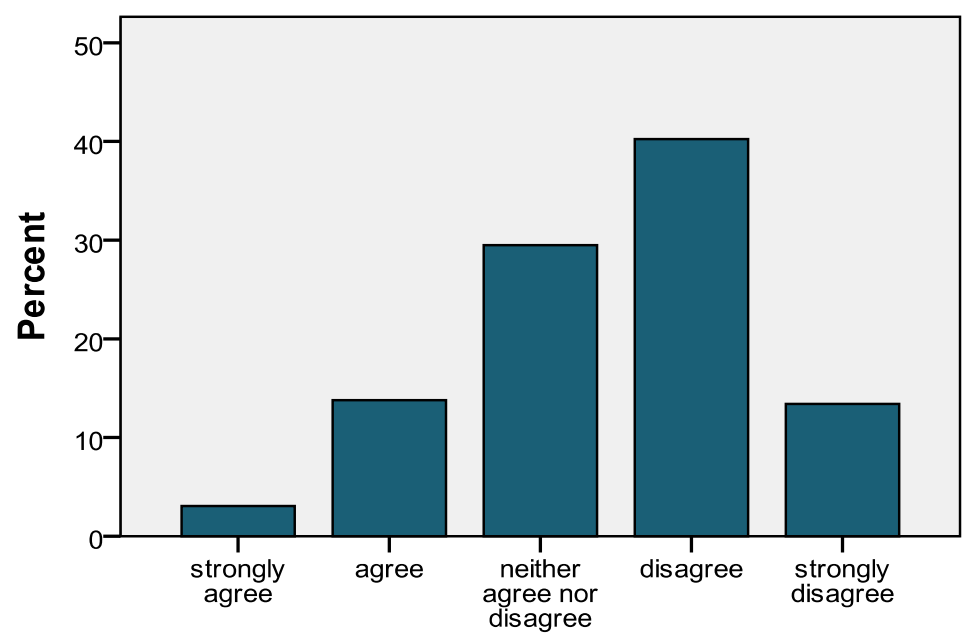

Figure 9. The authors sufficiently knowledgeable about ESD issues and methodology.

More than half of the respondents (59\%) claimed to find ESD implementation difficult to handle, whilst very few $(15.1 \%)$ believed that our current educational system is readily geared to facilitate ESD.

Educators' major preoccupation is their lack of preparation through valid training.

I do not know much about the subject. I need to know more and attend training as I really do not know where to start from (36 years, female, state school, and 13 years of teaching experience).

I would like to learn about how to do it in class. It is very difficult for me since the environment is not my area... I lack basic knowledge (32 years, male, church school, and 10 years of teaching experience).

Only a small percentage of the participants (25.5\%) to the quantitative study affirm that they feel that they were well trained on ESD while fulfilling their studies. 
Another strong concern expressed by the participants was the unavailability of adequate ESD resources and guidelines. While less than half of the participants feel the need to have a ready-made programme or syllabus in order to feel confident in delivering ESD, the majority of the participants claimed that they would benefit highly if given a locally valid toolkit with lesson plans and worksheets to follow (see Figure 10).

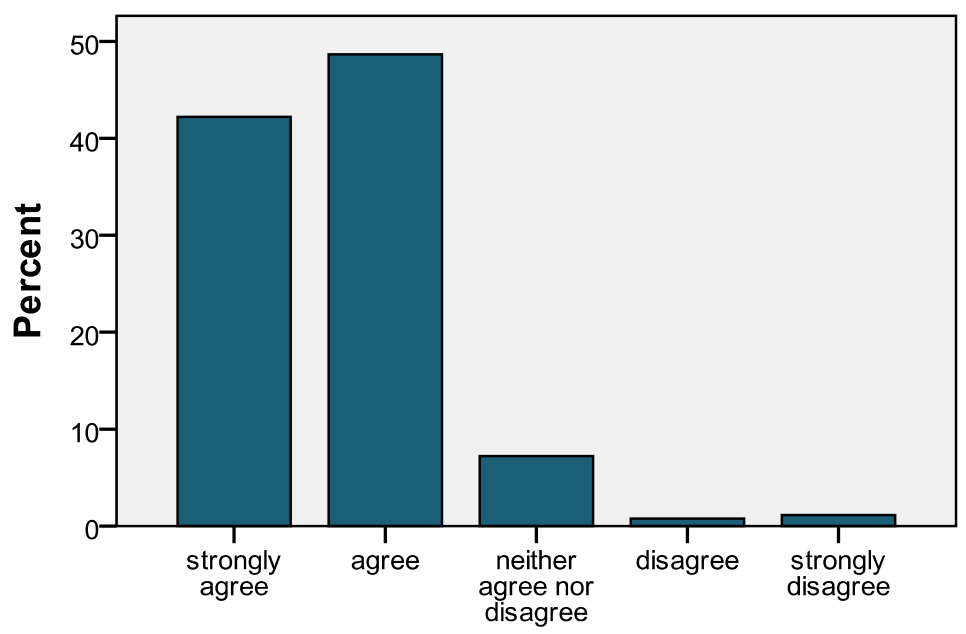

Figure 10. The authors would feel more confident in implementing ESD if a locally valid Toolkit with sample lesson plans and worksheets is available.

Some participants stated:

I wish I had some resources which could help me implement it. Presently, I cannot think of any and since I am not knowledgeable about the subject resources would help me a lot (33 years, female, independent school, and 11 years of teaching experience).

We have no resources at school about this subject. I try to look for information on Internet, but sometimes I do not know if they are valid or not for the Maltese context (25 years, female, church school, and two years of teaching experience).

The education department needs to give us samples of lesson plans which we could use in class. This can help me start doing more in this subject (47 years, female, state school, and 12 years of teaching experience).

I definitely need help to start doing ESD. A toolkit or resource pack would definitely make it easier to do ESD lessons and to learn how to go about them (43 years, male, state school, and 20 years of teaching experience).

Furthermore, almost three quarters (70.9\%) of the participants are willing to collaborate in shaping a culturally and socially valid toolkit. This lack of self-reliance in shaping lessons with ESD values in mind was also shown by the fact that more than half of the participants (56.5\%) to the study expressed the need of having an education officer or competent person guiding them in the transition. A large number of respondents expressed the need for syllabi and workbooks for other subjects to be shortened to allow more time for ESD (see Figure 11).

These results show these educators' inability to see ESD as a cross-curricular theme which could be easily integrated within many of the topics present in the subjects' syllabi.

Although all these ideas are interesting, I think that it is very difficult for me to include ESD in everyday teaching. I teach a year 5 class and it is a constant rush towards finishing what is on the syllabi for the exams (47 years, female, state school, and 12 years of teaching experience).

In-class contact time with pupils has been diminished. Students have P.E., Arts, and Music for which they are with other teachers. I use the remaining contact time with students to cover the important subjects, such as Maths, Maltese, and 
English (36 years, female, state school, and 13 years of teaching experience).

Sometimes, I come up with a novel idea to implement in class. Then something else crops up. We are constantly interrupted by extracurricular activities during Christmas, Easter, and so on. I have to give up the activity, because I do not have sufficient time to do it (24 years, male, state school, and one year of teaching experience).

Some participants manifested that their preoccupation in not being able to deliver ESD due to the increasing problems encountered in everyday classroom management due to different ability classes and learners coming for problematic social backgrounds.

As a teacher I have to keep up with teaching, with helping disadvantaged learners cope and with trying to teach pupils who sometimes come from very difficult social backgrounds. Sometime, pupils are so overwhelmed with their problems that they are insensitive towards the environment - they could not care less about the environment! (36 years, female, state school, and 14 years of teaching experience)

Others also mentioned that old school buildings which are not environmentally friendly.

I try to teach students practical ideas to help the environment and that we should respect the environment by for example closing the water taps, switching off the lights, and so on. However, sometimes, it is difficult to lead by example in an old school building like ours in which water taps are left dripping for a whole weekend sometimes as they are too hard to close by students. I think we need to start refurbishing old schools to make them look more sustainable (26 years, female, state school, and three years of teaching experience).

Some participants emphasised their inability to incorporate ESD in their teaching due to bureaucratic limitations and the huge amount of paper work they are expected to fill in.

We are inundated with paper work — writing reports on students with learning difficulties, filling in questionnaires and other office needed material, writing profiles... this leaves me very little time to prepare for another subject, such as ESD, as first I have to cater for the exam subjects which are the most important (36 years, female, state school, and 13 years of teaching experience).

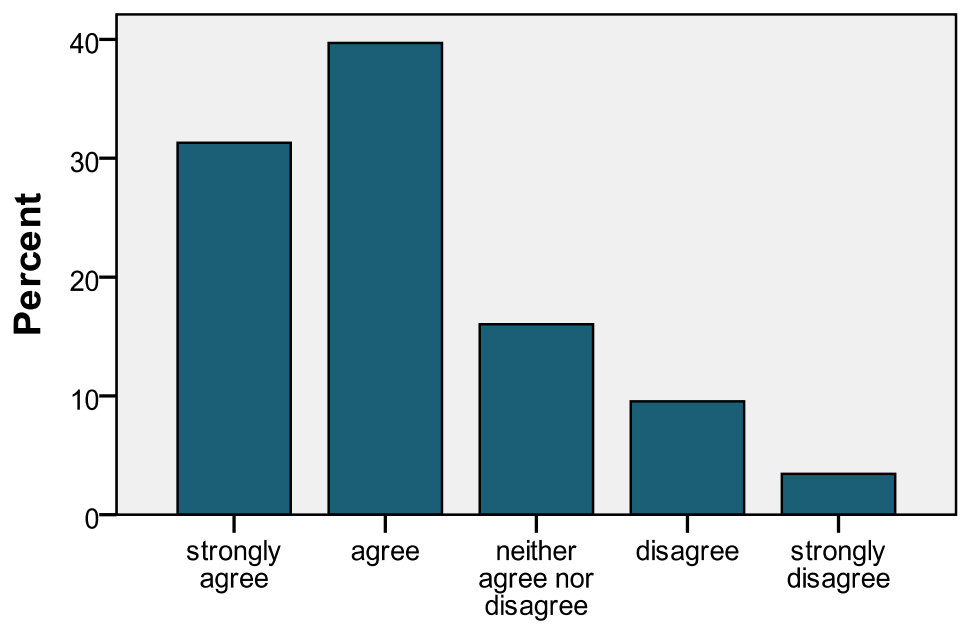

Figure 11. The authors would feel more confident in implementing ESD if syllabi and workbooks for other subjects are shortened to allow more time for ESD.

\section{Significant Differences That Emerged Between the Studied Variables}

This study also aimed to highlight any significant differences between the knowledge level, attitudes, and behaviour of the research variables that emerged. Various significant differences were reported according to 
age, gender, years of teaching experiences, school sector, and level of education.

Few noteworthy differences were recorded in analysing participants' knowledge of some ESD statements. Male participants believe that ESD engages formal, non-formal, and informal education $(p=0.006, \bar{x}$ male $=2$, $\bar{x}$ female $=1.629)$ and that ESD encourages learners to look at the roots of issues before taking action more than females ones do $(p=0.027, \bar{x}$ male $=1.945, \bar{x}$ female $=1.663)$.

Participants from independent schools seem to have a much higher recognition of ESD as a tool to achieve a more sustainable future than those from Church schools $(p=0.046, \bar{x}$ state school $=1.528, \bar{x}$ Church school $=$ $1.357, \bar{x}$ independent school $=1.833$ ). Furthermore, participants in the $36-48$ age group have a higher regard of ESD which prompts the individual in active involvement in the community than those in the 49-61 age group $(p=0.003, \bar{x} 22-35=1.762, \bar{x} 36-48=2.090, \bar{x} 49-61=1.565)$.

Various significant differences in the studied variables of participants' attitudes towards ESD emerged from this study. The participants' level of education highly determines how they approach this subject. Educators with other qualification rather than a bachelor's degree feel that: It is less important for primary school pupils to be involved in a myriad of ESD issues $(p=0.002, \bar{x}$ bachelor or equivalent $=3.247, \bar{x}$ other $=$ 3.794), and activities; it is better for ESD to be tackled by NGOs $(p=0.019, \bar{x}$ bachelor or equivalent $=2.418, \bar{x}$ other $=2.881)$; and that ESD should be given less importance than the core subjects $(p=0.006, \bar{x}$ bachelor or equivalent $=3.307, \bar{x}$ other $=2.725$ ). In addition, participants with a bachelor's degree or equivalent feel more open to attending introductory compulsory in-service training than those with other qualifications $(p=0.022, \bar{x}$ bachelor or equivalent $=2.338, \bar{x}$ other $=1.976$ ).

Teaching experience, age, school sector, and gender were also found to determine a difference in participants' attitudes towards ESD. Participants within the 22-35 age group are more insistent that ESD should be left for the secondary years of schooling than those in the 36-48 age group. Differences appeared between those in the 22-35 and 49-61 age groups, and those with a teaching experience of 0.5-4 years and 13 years or higher regarding the degree to which they consider ESD as significant as the core subjects $(p=0.017, \bar{x} 22-35=$ $3.975, \bar{x} 36-48=3.58, \bar{x} 49-61=3.8$ ). Participants from independent schools have a higher opinion of ESD as being vital for achieving sustainability than those in state schools $(p=0.000, \bar{x}$ state school $=2.041, \bar{x}$ Church school $=2.554, \bar{x}$ independent school $=2.700$ ). Female participants also give a higher ranking to the importance that ESD should be assessed by the end of year formal assessments than male participants $(p=0.038, \bar{x}$ male $=$ $3.769, \bar{x}$ female $=4.115$ ).

Significant differences in participants' behaviour of ESD arose from factors that determine age, teaching experience, and level of education. Age seems to be a prominent feature that affects educators' ESD behaviour. Substantial differences were recorded between participants in the 36-48 age group and those in the 22-35 bracket in relation to promoting the values of peace, solidarity, and mutual respect ( $p=0.044, \bar{x} 22-35=5.049$, $\bar{x} 36-48=4.702, \bar{x} 49-61=4.72)$, and to good listening and expression skills $(p=0.029, \bar{x} 22-35=5.049, \bar{x}$ $36-48=4.702, \bar{x} 49-61=5.0)$. Participants' behaviour of those with 13-18 years of teaching experience and those with $0.5-4$ differed in the way they promote a sense of community within their classroom $(p=0.033, \bar{x}$ $0.5-4=5.537, \bar{x} 5-8=5.333, \bar{x} 9-12=5.448, \bar{x} 13-18=5.183, \bar{x} 19-39=5.487)$, whilst those in the 49-61 and 22-35 age groups hold debate and discussion sessions on different levels $(p=0.044, \bar{x} 22-35=3.746, \bar{x} 36-48=$ $3.369, \bar{x} 49-61=3.32$ ).

Teaching experience also plays an important part in the way participants act. In fact, it seems that educators with a lower level of teaching experience are more open to use group work as a teaching and learning 
strategy and hold debate and discussion session $(p=0.037, \bar{x} 0.5-4=4.239, \bar{x} 5-8=3.667, \bar{x} 9-12=3.682, \bar{x}$ $13-18=3.915, \bar{x} 19-39=3.683$ ).

Teachers' level of education leads to differences in their ESD behaviour. The results established that participants with a bachelor's degree use role-play as a teaching strategy more than those with other qualifications $(p=0.050, \bar{x}$ bachelor or equivalent $=3.214, \bar{x}$ other $=2.884)$. On the other hand, participants with a bachelor's degree work less on evaluating the environmental impact of an activity or an outing or on minimising its environmental impact ( $p=0.035, \bar{x}$ bachelor or equivalent $=3.36, \bar{x}$ other $=3.884$ ). The same holds true in respect to educators' approach in prompting creativity since those with a bachelor's degree seem to engage less in it than those with other qualifications $(p=0.018, \bar{x}$ bachelor or equivalent $=4.5, \bar{x}$ other $=4.884)$.

\section{Correlations Between Variables}

Another aim of this research was to establish if a relationship exists between primary educators' knowledge of attitudes towards and behaviour in ESD. Some statistical significant results, even though weak, give insight on the relationship that might exist between these variables. Results show that some correlations suggest a relationship between educators' knowledge and attitudes while no relationship resulted between their knowledge and behaviour. Some correlations indicated that when the participants' knowledge is high, their attitudes are high. This might imply that knowledge of ESD reflects on the educators' attitudes. There was a weak negative correlation between the concept of ESD as a tool to achieve sustainability and the educator's unwillingness to deliver ESD due to personal values. This relationship shows that educators believe in ESD's potential and are willing to perform accordingly. Another weak negative correlation studied the relationship between knowledge and attitude. ESD related to the formal, non-formal and informal sector was correlated to educators' attitudes towards the actual implementation to be left for secondary and tertiary years of schooling. This correlation shows that educators clearly believe in the notion of ESD as a lifelong learning process. Even though these correlations are negative, the relationship between the variables shows that the respondents' high knowledge tends to prompt the participants in opposing beliefs that do not support ESD values.

Another significant result suggests that when educators' knowledge is high, their attitudes regarding responsibility towards ESD values of their pupils are high. This might result from the fact that educators feel more confident in delivering ESD. A moderate positive relationship between the participants' knowledge that ESD is a tool to achieve a more sustainable future and their responsibility level towards the sustainable values that their learners develop shows that their attitude regarding responsibility is founded on their knowledge. Inversely, another correlation showed that a wrong assumption can lead to the wrong attitudes. A positive relationship between their knowledge of ESD as primarily linked to the environment and their attitude in how ESD can be reflected within their school, even though weak, shows a correlation between how their wrong idea of the concept of ESD is reflected in their attitudes.

A positive correlation was discovered between educators' past training and ESD implementation (see Table 3). This correlation shows that educators who were given training while fulfilling their studies are more able to take up the challenge of ESD. This might indicate that training is conducive to better ESD implementation. Another positive correlation shows a link in how knowledge affects ESD implementation. Though on the weak spectrum, this relationship confirms that participants who feel to be more knowledgeable about the subject believe more in their abilities as ESD educators. Thus, it can be implied that good knowledge of ESD concepts can help educators break the barriers due to the lack of self-confidence in the area. 
Table 3

\section{Main Correlations Between Variables}

\begin{tabular}{|l|l|}
\hline Correlations & Results \\
\hline $\begin{array}{l}\text { I think that ESD should be tackled as a cross-curricular theme within } \\
\text { all subjects and school activities. }\end{array}$ & $\begin{array}{l}\text { Statistically significant very weak negative correlation } \\
(r=-0.155, p=0.012) .\end{array}$ \\
\cline { 1 - 1 } $\begin{array}{l}\text { Using data relating to aspects of sustainability during data handling } \\
\text { and analysis. }\end{array}$ & \\
\hline
\end{tabular}

ESD promotes values like solidarity, equality, democracy, respect, tolerance, and social justice.

Promoting values of peace, solidarity, and mutual respect.

ESD is a tool to achieve a more sustainable future.

I feel fully responsible for the sustainable values and practices that my learners develop throughout the scholastic year under my supervision.

A statistically significant moderate positive relationship $(r=0.261, p=0.000)$.

ESD is a tool to achieve a more sustainable future.

I feel unwilling to deliver ESD as I do not share the same values and perspectives.

a statistically significant weak negative relationship $(r=-0.165, p=0.008)$

ESD is mostly teaching about the natural surroundings.

I feel making the learners aware of some environmental problems A statistically significant weak positive relationship and having a renewable energy sustainable school building and recycling bins is enough at primary level.

I feel I was well trained to implement ESD while fulfilling my studies in becoming an educator.

Presently, do you find it easy to implement ESD.

A statistically significant moderate positive correlation $(r=0.267, p=0.000)$

ESD engages the formal, non-formal, and informal education.

I think ESD should be left for the secondary and tertiary years of schooling.

A statistically significant very weak negative relationship $(r=-0.190, p=0.002)$.

\begin{tabular}{|l|l|}
\hline I feel sufficiently knowledgeable about ESD issues and methodology. & $\begin{array}{l}\text { A statistically significant weak positive correlation } \\
(r=0.248, p=0.000) .\end{array}$ \\
\hline Presently, do you find it easy to implement ESD. & $\begin{array}{l}\text { A statistically significant very weak negative relationship } \\
(r=-0.194, p=0.001) .\end{array}$ \\
\hline $\begin{array}{l}\text { I would feel more confident in implementing ESD if I attend an } \\
\text { introductory compulsory in-service training. }\end{array}$ & \begin{tabular}{l} 
Presently, do you find it easy to implement ESD. \\
\hline
\end{tabular}
\end{tabular}

A weak negative correlation between knowledge of ESD as a value oriented subject with educators' behaviour of promoting such values resulted. Furthermore, a weak negative relationship stemmed out of correlating the knowledge concept ESD as fostering environmentally responsible behaviours and enhancing pupils' skill in evaluating and trying to minimise the environmental impact of an outing. These two correlations denote that there is no relationship between the knowledge and the behaviour exhibited by the participants. 


\section{Discussion}

As demonstrated by the findings of this study Maltese junior years' educators' overall perceptions on ESD are limited or unclear. Their level of awareness and knowledge of the various concepts of EE/ESD are highly disjointed and fragmentary as teachers possess knowledge on some important aspects concerning ESD but are misinformed on many others. Furthermore, ESD is primarily regarded as a knowledge-oriented subject to be tackled in the years of formal schooling. Even though knowledge is not necessarily conducive to changing one's behaviour, this study shows that a lack of it seems to intimidate educators in trying to implement effective ESD in their daily teaching practice. This calls for the provision of further compulsory training from the part of the education department.

To the contrary, a positive attitude towards ESD implementation is manifested by the participants. In general, junior years' primary school teachers show eagerness and interest in implementing EE/ESD. This study shows that their attitude is positive and they show willingness to learn about and adopt ESD within their teaching strategies. This attitudes also transpires in the general need for ESD training and guidelines which prevailed amongst respondents.

This study revealed that many obstacles hinder holistic ESD implementation. The main limitations faced by educators in fully integrating EE/ESD are absence of knowledge, lack of self-confidence in the area, and the inability to visualise EE/ESD as a cross-curricular theme which can be incorporated within their present classroom practice.

Despite this, many educators amalgamate ESD methodological skills and values into their daily teaching strategies. It was noted that many primary educators do this without being aware of. Consequently, this is not being done to its full potential. The urgent need for training which highlights effective methodological skills in which educators can incorporate ESD knowledge and skills within the present topics of the syllabi is highlighted.

This study revealed various significant differences according to age, gender, years of teaching experiences, school sector, and level of education. These findings might give an indication to the Ministry of Education and the University of Malta as to which factors need to be targeted during the provision of ESD training.

The study also revealed a relationship between the following factors: educators' knowledge and attitudes; educators' knowledge and level of responsibility towards ESD implementation; and educators' training level and ESD implementation. Notwithstanding this, results imply that there is no relationship between educators' knowledge and behaviour. It was established that overall educators' attitudes were high, their knowledge of EE/ESD was low and their behaviour, although not satisfactory, was of a higher level than that of knowledge. However, despite the negative relationship that exists between knowledge and behaviour, it was noted that some behaviours that did not reflect an ESD ethos might reflect an unclear understanding of EE/ESD concepts on the part of educators. Even though it is widely established that knowledge is not necessarily conducive to a change in behaviour, there is no doubt that these educators urgently require to be informed about EE/ESD concepts and issues. Moreover, primary educators need preparation in methodological skills conducive to EE/ESD ethos in which values and skills through critical and creative learning experiences prevail over knowledge oriented top-down instruction approaches. They also need to see the importance of a sustainable lifestyle themselves since good ESD stems out of role modelling of positive behaviours (see Figure 12). 


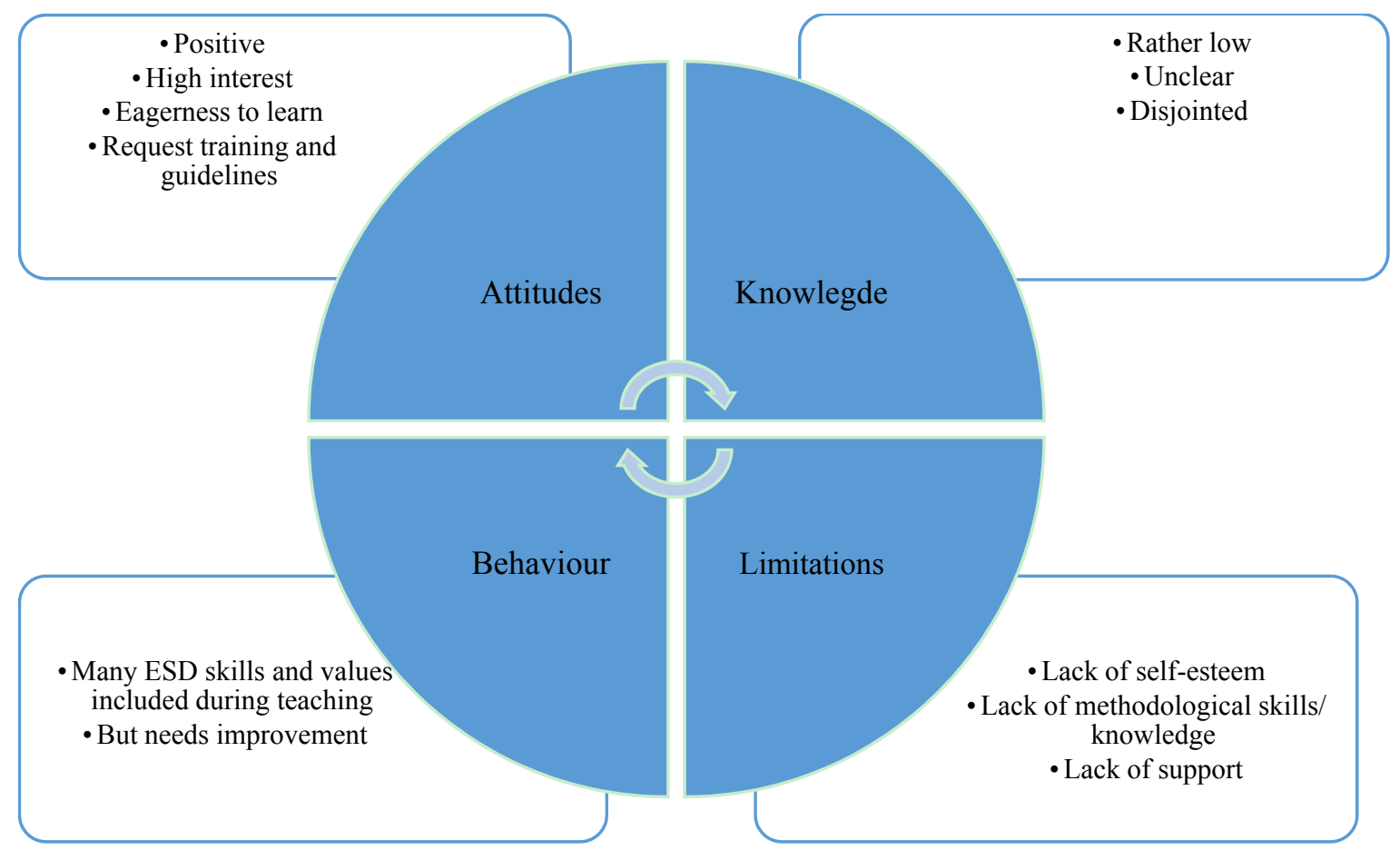

Figure 12. Model of results from the study.

\section{Conclusions}

This study has analysed primary junior years' teachers' perceptions of ESD through studying their attitudes, knowledge, and behaviour towards the area. It has included facets of EE and ESD since both areas are interconnected.

The results presented suggest that these educators show a predisposition to implement ESD within their classroom setting. This readiness is however hindered by various factors which show a lack of: knowledge in EE/ESD concepts; methodological skills for delivering EE/ESD; and limited training possibilities, resources, and guidelines in the area.

Some correlations to the results of this study suggest that there is a relationship between the knowledge and attitudes of educators while there is no relationship between their knowledge and their behaviour.

Thus, it can be concluded that junior years' primary school educators are not yet ready to take up the challenge of EE/ESD to the full. Educators' willingness to deliver EE/ESD suggests that their lack of confidence in the area and limited knowledge confines their implementation of the subject. Thus, they need extensive support and training in all areas of EE/ESD.

The following model is a synopsis of the outline of the findings gathered through this quantitative study.

\section{Recommendations}

The following are some recommendations that could enhance ESD implementation in Maltese primary schools. It would be beneficial if:

ESD teacher-training for primary school teachers is scheduled on a compulsory and voluntary basis. Such training needs to expose teachers to the importance of sustainability on a personal basis and move on to ESD skills and practices in the form of hands on sessions. 
Teachers' interest in attending already available training is enhanced through the use of emails that inform them about the positive aspects of such programs.

ESD competent persons are allocated to each school college to monitor and guide interested teachers in their implementation of ESD through a tutoring system. This team could be made up of teachers who already use good ESD methodology skills in their daily practice.

A syllabus or sample scheme of work is devised by a team of teachers who already grasped ESD methodological skills. It would be better if such a resource presents a set of ESD values and skills to be taught rather than topics, in the expectation that teachers amalgamate them into their already-set agenda in a cross-curricular manner.

Training at the University of Malta gives students the possibility to experience ESD as a cross-curricular area.

An ESD teachers' blog, Internet page, or Facebook page is set up to help Maltese teachers easily connect with each other. Such a platform would serve Maltese primary educators to collaborate in exchanging ideas, articles, and resources that enhance ESD implementation.

Schools collaborate with local councils and other local social entities in order to organise events that boost the interest of the community in sustainable practices.

\section{References}

Adawiah, J., \& Norizan, E. (2012). Teachers' knowledge of education for sustainable development. UMT 11th International Annual Symposium on Sustainability Science and Management, Terengganu, Malaysia.

Aguis, C., Chetcuti, J., \& Galea, T. (1996). Environmental education in primary schools: A cross-curricular approach (Unpublished degree dissertation, University of Malta, Malta).

Athanasios, K., Polyxeni, R., \& Anastasios, P. (2006). Study of primary and secondary environmental educators' understanding of sustainable development, education for sustainable development and its relation with environmental education. In Sustainable management and development of mountainous and island areas. student study of forest recreation, environmental education, and sociology (pp. 181-188). School of Forestry and Natural Environment, Aristotle University of Thessaloniki.

Baldacchino, F. (2011). Attitudes of primary school children towards environmental responsibility (Unpublished degree digital dissertation, University of Malta, Malta).

Buchanan, J. (2012). Sustainability education and teacher education: Finding a natural habitat? Australian Journal of Environmental Education, 28(2), 108-124. doi: http://dx.doi.org.ejournals.um.edu.mt/10.1017/aee.2013.4

Buhagiar, S., \& Gatt, A. (2006). My town/my village: Curriculum pack for the EkoSkola Programme (Unpublished degree dissertation, University of Malta, Malta).

Bursjoo, I. (2011). How student teachers form their educational practice in relation to sustainable development. Utbildning \& Demokrati, 20(1), 59-78. Retrieved from http:/www.oru.se/English/Research/Research-Environments/Researchenvironment/HS/Education-and-Democracy/Education-Democracy/

Chunteng, L. (2004). Survey of primary and secondary school teachers' teaching competence for environmental education in Xicheng District of Beijing. Chinese Education \& Society, 37(4), 39-44. Retrieved from http://web.a.ebscohost.com. ejournals.um.edu.mt/ehost/detail/detail?sid=3af2355d-a033-4f54-9b23-71860bbf56a3\%40sessionmgr4001\&vid=0\&hid=420 6\&bdata=JnNpdGU9ZWhvc3QtbG12ZQ\%3d\%3d\#db=a9h\&AN=15017145

McKeown, R. (2002). Education for sustainable development toolkit. Retrieved from http://www.esdtoolkit.org/

Michail, S., Stamou, A. G., \& Stamou, G. P. (2006). Greek primary school teachers' understanding of current environmental issues: An exploration of their environmental knowledge and images of nature. Science Education, 91(2), 244-259. doi: 10.1002/sce.20185.

Mifsud, M. (2011). An investigation on the environmental knowledge, attitudes and behaviour of Maltese youth. US-China Education Review B, 1(3), 413-422. Retrieved from http://files.eric.ed.gov/fulltext/ED524899.pdf

Mifsud, M. (2012). Environmental education development in Malta: A contextual study of the events that have shaped the development of environmental education in Malta. Journal of Teacher Education for Sustainability, 14(1), 5-79. doi: 10.2478/v10099-012-0004-x 
Ministry of Education: Malta. (1999). Creating the future together: National Minimum Curriculum. Retrieved from http://www.curriculum.gov.mt/docs/nmc_english.pdf

Ministry of Education and Employment (MEE): Malta. (2012). National Curriculum Framework for All. Retrieved from http://www.file:///C:/Users/schools_home/Downloads/NCF\%20(6).pdf

Pace, P., \& Brigulio, L. (2004). Education for sustainable development in Malta. In University of Malta. Retrieved from http://www.um.edu.mt/_data/assets/pdf_file/0006/63861/education_esd_lbriguglio_ppace.pdf

Portelli, N. (2011). Attitudes towards environmental responsibility in secondary schools (Unpublished degree digital dissertation, University of Malta, Malta).

Robertson, C. L., \& Krugly-Smolska, E. (1997). Gaps between advocated practices and teaching realities in environmental education. Environmental Education Research, 3(3), 311-326. doi: 10.1080/1350462970030305

Ryan, A. (2004). Student teachers' attitudes towards education for sustainable development. In S. Catling, \& F. Martin (Eds.), Researching primary geography (Vol. 1, pp. 225-234). Special Publication. Retrieved from http://www .geography.org.uk/ eyprimary/primaryresearch/researcharticles/

Saka, A., \& Sahintürk, A. (2013). Attitudes of prospective forest engineers and primary school teachers towards a sustainable environment. Pol. J. Environ. Stud., 22(50), 1533-1557. Retrieved from http://web.b.ebscohost.com.ejournals.um.ed u.mt/ehost/pdfivewer/pdfviewer?sid=00fdd6fd-3b03-44f1-9cd0b4806ac96f2a\%40sessionmgr1 13\&vid=1\&hid=101

Stevenson, R., Brody, M., Dillon, J., \& Wals, A. (2013). International handbook of research on environmental education. U.K.: Routledge.

United Nations Educational, Scientific, and Cultural Organization [UNESCO]. (2006). Education for sustainable development toolkit: United Nations decade of education for sustainable development (2005-2014). UNESCO: Section for Education for Sustainable Development, France.

Ventura, F. (1994). Environmental education in small island developing states. In W. L., Filho (Ed.), The commonwealth of learning. Canada: The Commonwealth of Learning.

Wals, A., \& Kieft, G. (2010). Education for sustainable development: Research overview. Sida Review, 13. Sida, Stockholm: Swedish International Development Cooperation Agency. 